\title{
Effects of PEEP on inspiratory resistance in mechanically ventilated COPD patients
}

\author{
C. Guérin*, G. Fournier*, J. Milic-Emilï
}

Effects of PEEP on inspiratory resistance in mechanically ventilated COPD patients. C. Guérin, G. Fournier, J. Milic-Emili. (C)ERS Journals Ltd 2001.

ABSTRACT: This study aimed to investigate the effect of increased lung volume with positive end-expiratory pressure (PEEP) on respiratory resistance in patients with chronic obstructive pulmonary disease (COPD).

Ten patients with COPD were mechanically ventilated for acute respiratory failure. PEEP was set at $0,5,10$ and $15 \mathrm{cmH}_{2} \mathrm{O}$. Using the rapid airway occlusion technique, the total inspiratory resistance of the respiratory system was partitioned into interrupter $(R$ int,rs $)$ and additional effective $(\Delta R \mathrm{rs})$ resistances. At each level of PEEP, at constant inflation flow, the inflation volume $(\Delta V)$ was varied from $0.2-1 \mathrm{~L}$, and, at constant $\Delta V$, the inflation flow was varied from $0.2-1.2 \mathrm{~L} \cdot \mathrm{s}^{-1}$. The changes in end-expiratory lung volume ( $\triangle E E L V)$ induced by PEEP were also measured.

The difference between the EELV and the relaxation volume of the respiratory system ( $\triangle F R C)$ increased significantly with PEEP of 10 and $15 \mathbf{c m H}_{2} \mathrm{O}$ as compared to a PEEP of 0 , the increase being associated with a significant reduction of $R$ int,rs. By contrast, $\Delta R$ rs was independent of $\Delta F R C$. At constant $\Delta V$, Rint,rs fitted Rohrer's equation (Rint,rs $=K_{1}+K_{2} \times$ flow). While $K_{2}$ significantly declined with $\Delta F R C, K_{1}$ did not change. At all levels of PEEP, $\Delta R$ rs was not influenced by $\triangle F R C$.

With increasing lung volume induced by positive end-expiratory pressure, the inspiratory airway resistance decreased, whereas the viscoelastic behaviour of the respiratory system, as reflected by additional effective resistance, did not change. Eur Respir J 2001; 18: 491-498.

In recent years, the rapid airway occlusion (RAO) technique has been extensively used in mechanically ventilated subjects to partition the total inspiratory resistance (Rrs) into: 1) the interrupter resistance (Rint,rs), which in humans mainly reflects airway resistance; and 2) the additional effective inspiratory resistance $(\Delta R \mathrm{rs})$ that results from dynamic pressure dissipation due to the viscoelastic properties of the thoracic tissues and time constant inequality within the lung $[1,2]$. These studies have shown that $\Delta R \mathrm{rs}$ represents a large fraction of $R$ rs in both normal subjects and patients [1-3]. In normal subjects, both at zero end-expiratory pressure (ZEEP) and at increased lung volume with positive end-expiratory pressure (PEEP) of $8 \mathrm{cmH}_{2} \mathrm{O}$, the changes in $\Delta R$ rs with flow and volume can be satisfactorily explained by a simple four-parameter linear viscoelastic model of the respiratory system [4]. In contrast, in patients with acute respiratory distress syndrome (ARDS), even on ZEEP, the model fails to account for the changes in $\Delta R$ rs when the inflation volume exceeds $0.7 \mathrm{~L}$ [5]. Whether this reflects nonlinear viscoelastic behaviour of the stress relaxation units of the injured lung, or other factors, remains to be elucidated. In mechanically ventilated patients with chronic obstructive pulmonary disease (COPD), the effect of PEEP on $\Delta R \mathrm{rs}$ has also been studied. In one study, by experimental design, the maximal applied PEEP was limited to $86 \%$ of the intrinsic PEEP [6]. Under the latter conditions, the changes in end-expiratory lung volume (EELV) were necessarily very small (mean of $0.13 \mathrm{~L}$ ), and accordingly in that study, there was little or no change of $\Delta R \mathrm{rs}$ and $R$ int,rs. In another study, PEEP was applied up to $15 \mathrm{cmH}_{2} \mathrm{O}$ [7]. The authors observed a significant reduction of lung interrupter resistance (Rint) and a significant increase of lung additional resistance with PEEP [7]. However, these measurements were performed at fixed inflation flow and volume [7]. In addition, in the latter study [7] the authors did not assess the change in lung volume elicited by PEEP. Consequently, the volume-dependence of $\Delta R \mathrm{rs}$ in COPD patients remains to be determined in experiments in which high levels of PEEP are applied to induce marked changes in lung volume.

The purpose of the present investigation was to assess in COPD patients, using the RAO technique, the effects of increasing lung volume with PEEP up to $15 \mathrm{cmH}_{2} \mathrm{O}$ on $\Delta R \mathrm{rs}$ and $R$ int,rs, and to analyse the data in terms of the four-parameter linear viscoelastic model of the respiratory system $[1,8]$. 


\section{Methods}

Ten male COPD patients with acute respiratory failure (ARF) requiring tracheal intubation and mechanical ventilation were investigated. Their anthropometric characteristics are given in table 1 . Patients were studied 1-10 days after the onset of mechanical ventilation (mean $\pm \mathrm{SD}$ : $3 \pm 2.5$ days). The diagnosis of COPD was made according to clinical history, chest radiography and pulmonary function tests. The mean values of forced expiratory volume in one second (FEV1) and vital capacity (VC) before ARF were $0.89 \pm 0.36 \mathrm{~L}(31 \pm 18 \%$ pred $)$ and $2.13 \pm 0.72 \mathrm{~L}(51 \pm 21 \%$ pred), respectively [9]. ARF had been triggered by lower respiratory tract infection in four patients, pneumonia in three and pleural effusion in one; no aetiological factor was found in the remaining two patients. The investigation was approved by the Institutional Ethics Committee in Lyon, and informed consent was obtained from the next of kin for each patient. The effects of PEEP on alveolar recruitment, closing volume and haemodynamics on the patients of this study have been previously reported [10].

The patients were orotracheally intubated (Mallinckrodt $\AA$ cuffed-endotracheal tube of 7.5, 8 or $8.5 \mathrm{~mm}$ internal diameter (ID) and $35 \mathrm{~cm}$ length; Mallinckrodt laboratories, Athlone, Ireland) and mechanically ventilated in synchronized intermittent mandatory volume (SIMV) mode with a squarewave inspiratory flow (Siemens-Elema 900 C ServoVentilator; Solna, Sweden). During the study all patients were sedated with midazolam $\left(0.2 \mathrm{mg} \cdot \mathrm{kg}^{-1}\right)$ and paralyzed with atracurium $\left(0.3-0.6 \mathrm{mg} \cdot \mathrm{kg}^{-1}\right)$. The baseline ventilatory settings, which were kept constant throughout the experiment, are listed in table 1 . The inspiratory duty cycle $(t \mathrm{I} / t$ tot $)$ was $0.25 \pm 0.03$. Airflow $\left(V^{\prime}\right)$ was measured with a heated pneumotachograph (Fleisch No.2; Fleisch, Lausanne, Switzerland) inserted between the endotracheal tube and the Y-piece of the ventilator. The pressure drop across the two ports of the pneumotachograph was measured with a differential piezoelectric pressure transducer (163PC01D36, $\pm 12.7 \mathrm{cmH}_{2} \mathrm{O}$; Micro switch Freeport, IL, USA). The response of the pneumotachograph was linear over the experimental range of $V^{\prime}$. Pressure at the airway opening $(P \mathrm{ao})$ was measured proximal to the endotracheal tube with a piezoelectric pressure transducer (143PC03D, $\pm 176 \mathrm{cmH}_{2} \mathrm{O}$; Micro switch). Tracheal pressure $(P \operatorname{tr})$ was measured via a polyethylene catheter ( $1.5 \mathrm{~mm}$ ID) with multiple side holes and an occluded end hole, placed $2 \mathrm{~cm}$ past the carinal end of the endotracheal tube and connected to a piezoelectric pressure transducer (143PC03D, $\pm 176 \mathrm{~cm} \mathrm{H}_{2} \mathrm{O}$; Micro switch). With the system used to measure $P$ ao and $P$ tr, there was no appreciable shift or alteration in amplitude up to $20 \mathrm{~Hz}$. The equipment dead space (not including the endotracheal tube) was $150 \mathrm{~mL}$. All variables were recorded on an IBM compatible computer by a 12-bit analogue-digital board (DT2801-A) interfaced with data acquisition software (Labdat ${ }^{\text {TM }}$ RHT-Infodat Inc., Montreal, Canada) at a sample frequency of $100 \mathrm{~Hz}$. Subsequent data analysis was made with Anadat $\mathrm{Tb}$ (RHT-Infodat Inc.). In this analysis, $\Delta V$ was obtained by digital integration of the $V^{\prime}$ signal. Special care was taken to avoid gas leaks in the equipment and around the tracheal cuff.

Measurements were made at four nominal levels of PEEP $\left(0,5,10,15 \mathrm{cmH}_{2} \mathrm{O}\right)$, except for patient No. 2, in whom $15 \mathrm{cmH}_{2} \mathrm{O}$ PEEP was not applied. PEEP was applied in random order for 15-20 min. Patients were judged to have reached a steady state by stability of haemodynamic measurements and pulse oximetry records. During the study, a physician not involved in the experiment was always present to provide patient care.

\section{Procedure and data analysis}

Patients were investigated supine. The measurements of respiratory mechanics were made at the end of each 15-20 min period of PEEP. Respiratory mechanics were assessed by the constant-flow RAO method [1-3]. The two following sets of experiments were performed in each subject at each level of PEEP. 1) Iso- $\Delta V$ experiment: while baseline $\Delta V$ was kept constant, $V^{\prime}$ was varied randomly from $0.2-1.2 \mathrm{~L} \cdot \mathrm{s}^{-1}$ for single test breaths, by regulating $t \mathrm{I}$ with the appropriate knob of the ventilator. 2) Iso- $V^{\prime}$ experiment: while baseline $V^{\prime}$ was kept constant, $\Delta V$ was changed randomly from $0.2-1$ L for single test breaths by changing the frequency of the ventilator.

The end-inspiratory occlusion, obtained by pressing the end-inspiratory hold knob on the ventilator, lasted $5 \mathrm{~s}$. Before each test breath an end-expiratory occlusion was performed by pressing the end-expiratory hold knob on the ventilator. This allowed quantification of intrinsic positive end-expiratory pressure (PEEPi) and to start the test breath from a fixed static elastic equilibrium condition. When PEEP was applied, the end-expiratory occlusion pressure was the sum of the PEEP set by the ventilator and PEEPi. This

Table 1. - Anthropometric characteristics and baseline ventilatory settings of 10 chronic obstructive pulmonary disease (COPD) patients

\begin{tabular}{|c|c|c|c|c|c|c|c|c|c|c|}
\hline & \multirow[t]{2}{*}{ Age yrs } & \multirow[t]{2}{*}{ Height $\mathrm{cm}$} & \multicolumn{2}{|c|}{ Weight } & \multirow{2}{*}{$F \mathrm{I}, \mathrm{O}_{2} \%$} & \multirow[t]{2}{*}{$\Delta V \mathrm{~L}$} & \multirow[t]{2}{*}{$V^{\prime} \mathrm{L} \cdot \mathrm{s}^{-1}$} & \multirow[t]{2}{*}{ TI s } & \multirow[t]{2}{*}{$T \mathrm{E} \mathrm{s}$} & \multirow[t]{2}{*}{$f \mathrm{R} \min ^{-}$} \\
\hline & & & $\mathrm{kg}$ & $\left(\%\right.$ pred $\left.^{\#}\right)$ & & & & & & \\
\hline Mean & 64 & 167 & 72 & 96 & 48 & 0.74 & 0.65 & 1.13 & 3.42 & 13.5 \\
\hline SD & 6 & 6 & 21 & 27 & 9 & 0.09 & 0.12 & 0.15 & 0.57 & 1.5 \\
\hline
\end{tabular}

$F \mathrm{I}, \mathrm{O}_{2}$ : fraction of inspired oxygen; $\Delta V$ : inflation volume; $V^{\prime}$ : inflation flow; $T \mathrm{I}$ : inspiratory time; $T \mathrm{E}$ : expiratory time; $f \mathrm{R}$ : respiratory frequency. ${ }^{\#}$ : predicted values from [9]. 
sum was termed total PEEP (PEEPt). It should be noted that on ZEEP, the ventilator generated a slight PEEP, averaging $0.9 \pm 0.6 \mathrm{cmH}_{2} \mathrm{O}$. Accordingly, PEEPt was also measured on ZEEP. Since PEEPi implies dynamic pulmonary hyperinflation (i.e. that EELV during mechanical ventilation exceeds the relaxation volume of the respiratory system $\left.\left(V_{\mathrm{r}}\right)\right)$, the difference between EELV and $V_{\mathrm{r}}$ (termed $\triangle \mathrm{FRC}$ here) was also measured by reducing the ventilator frequency to its lowest value $\left(1 \mathrm{breath} \cdot \mathrm{min}^{-1}\right)$ during the baseline expiration on SIMV, thus prolonging expiratory duration to allow the patient to exhale to $V \mathrm{r}$. The $V \mathrm{r}$ was achieved when expiratory flow became nil and end-expiratory occlusion resulted in no change in airway pressure (i.e. no PEEPi). After each test breath, the baseline ventilation was resumed until $\Delta V$, $V^{\prime}$ and pressures returned to their baseline values (usually in a few breaths). Each measurement was carried out twice.

After end-inspiratory airway occlusions, $P \operatorname{tr}$ and $P$ ao exhibited an initial rapid drop (maximal pressure $(P \max )-P 1)$ followed by a slow decay to an apparent plateau pressure $\left(P_{\text {st,rs }}\right)$. During this period, the contribution of reduction in pressure due to volume loss by continuing gas exchange should be negligible. By dividing (maximal tracheal pressure $\left.\left(P_{\max }, \mathrm{tr}\right)-P_{\text {st,rs }}\right)$ by the $V^{\prime}$ immediately preceding the end-inspiratory occlusion, the total inspiratory resistance of the respiratory system $(R \mathrm{rs})$ was obtained. By dividing $\left(P\right.$ max,tr- $P 1$,tr) by the $V^{\prime}$ immediately preceding the end-inspiratory occlusion, Rint,rs was obtained. After airway occlusion, $P \operatorname{tr}$ showed some oscillations due to inertia (immediately after occlusion) and heart beats; these were allowed for by fitting a smooth curve to the pre- and postocclusion portions of the $P \operatorname{tr}$ signal and by back extrapolation of the curvilinear computerfitted curves to the point in time when the occlusion valve was half closed to obtain $P \max$ and $P 1$, respectively $[2,11]$. This was achieved by using Anadat (RHT-lnfodat). In computing Rint,rs, the errors caused by the closing time of the ventilator valve were corrected as previously described [12]. The $\Delta R$ rs was computed as the difference between $R$ rs and $R$ int,rs. The static elastance of the respiratory system $(E$ st,rs $)$ was computed dividing $(P$ st,rs-PEEPt $)$ by $\Delta V$.

\section{Model and curve fitting}

Data were analysed in terms of the viscoelastic model of the respiratory system depicted in figure 1 [1]. This model comprises two parallel compartments. The first is a dashpot representing Rint,rs, which explains the initial fast drop observed in respiratory system pressure $(P$ rs $)$ immediately after the endinspiratory occlusion. Rint,rs is the sum of the interrupter resistance of lung and chest wall. Contrary to in dogs [13], in normal anaesthetized paralysed humans [2] and in COPD patients [3], the chest wall does not contribute substantially to Rint,rs, and essentially reflects the airway resistance. The second compartment of the model in figure 1 is a Kelvin body, which consists of a standard static elastance $\left(E_{\mathrm{st}, \mathrm{rs}}\right)$ in parallel with a Maxwell body, i.e. a spring,

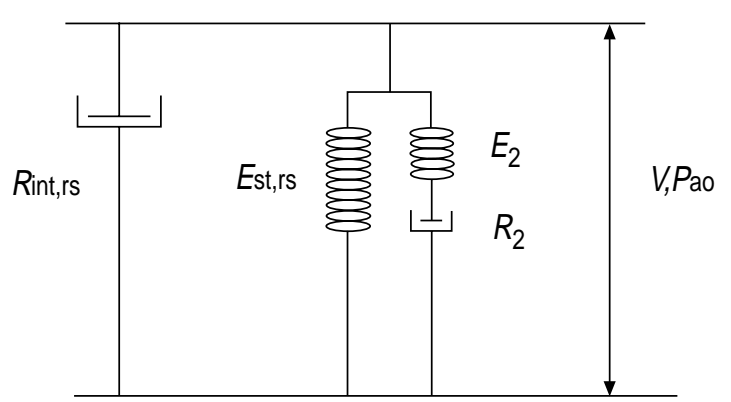

Fig. 1.-Scheme of spring-and-dashpot model for interpretation of respiratory mechanics during constant flow interruption. The respiratory system consists of standard resistance (Rint,rs) in parallel with standard elastance $\left(E_{\mathrm{st}, \mathrm{rs}}\right)$ and a series of spring-anddashpot body ( $E_{2}$ and $R_{2}$, respectively) that represents stress adaptation units. Distance between the two horizontal bars is the analogue of lung volume $(V)$ and tension between these bars is the analogue of pressure at the airway opening $(P$ ao $)$.

$E_{2}$, and a dashpot, $R_{2}$, arranged serially. In normal anaesthetized, paralysed subjects and in COPD patients, $E_{2}$ and $R_{2}$ mainly reflect the viscoelastic properties of the tissues of the lungs and chest wall [2]. In COPD patients, however, part of $E_{2}$ and $R_{2}$ is also due to time constant inequalities in the lungs [3].

During constant- $V^{\prime}$ inflation, the model in figure 1 predicts that $\Delta R$ rs should increase with $t$ I according to the following function [1]:

$$
\Delta R_{\mathrm{rs}}=R_{2} \times\left(1-\exp ^{\left(-t_{1} / \tau_{2}\right)}\right)
$$

where the time constant $\left(\tau_{2}\right)$ is equal to $R_{2} / E_{2}$.

Since during constant- $V^{\prime}$ inflation $T l=\Delta V / V^{\prime}$, equation 1 can be rewritten [1]:

$$
\Delta R_{\mathrm{rs}}=R_{2} \times\left(1-\exp ^{(\Delta V / V \ni \tau 2)}\right)
$$

The values of $R_{2}$ and $T_{2}$ were obtained by fitting the experimental data to equations 1 and 2 .

\section{Statistical analysis}

Regression analysis was performed using a mixed linear model with random intercept and random slope. The values of respiratory mechanics obtained at the different levels of PEEP were compared using two-way analysis of variance for repeated measures (ANOVA). The values at each level of PEEP were compared to those on ZEEP using the paired t-test of Dunnett [14]. Comparison between groups was made using the Student's t-test. A p-value $<0.05$ was accepted as statistically significant. Values are expressed as mean $\pm \mathrm{SD}$.

\section{Results}

The difference between end-expiratory lung volume and the relaxation volume of the respiratory system

As shown in table 2, $\triangle F R C$ increased at all levels of PEEP, but the increase was significant only at PEEP $>5 \mathrm{cmH}_{2} \mathrm{O}$. The latter reflects the marked difference in the magnitude of PEEPi among the COPD patients 
Table 2. - Baseline respiratory mechanics data at different positive end expiratory pressure (PEEP) levels

\begin{tabular}{|c|c|c|c|c|}
\hline & \multicolumn{4}{|c|}{ PEEP $\left(\mathrm{cmH}_{2} \mathrm{O}\right)$} \\
\hline & 0 & 5 & 10 & 15 \\
\hline PEEPt $\mathrm{cmH}_{2} \mathrm{O}$ & $8.4 \pm 4.8$ & $10.0 \pm 3.9$ & $12.3 \pm 2.4^{*}$ & $16.9 \pm 1.8^{* *}$ \\
\hline PEEPi $\mathrm{cmH}_{2} \mathrm{O}$ & $7.1 \pm 3.9$ & $3.7 \pm 3.3$ & $1.8 \pm 1.8 * *$ & $0.8 \pm 1.2 * *$ \\
\hline$\Delta \mathrm{FRC} \mathrm{L}$ & $0.54 \pm 0.42$ & $0.74 \pm 0.48$ & $1.03 \pm 0.42 * *$ & $1.50 \pm 0.51 * *$ \\
\hline$R$ int,rs $\mathrm{cmH}_{2} \mathrm{O} \cdot \mathrm{L}^{-1} \cdot \mathrm{s}$ & $9.2 \pm 3.6$ & $8.1 \pm 2.7$ & $7.3 \pm 2.7$ & $7.2 \pm 3.0$ \\
\hline$\Delta R \mathrm{rs} \mathrm{cmH}_{2} \mathrm{O} \cdot \mathrm{L}^{-1} \cdot \mathrm{s}$ & $7.7 \pm 1.8$ & $8.5 \pm 1.8$ & $9.5 \pm 2.7$ & $9.7 \pm 3.3$ \\
\hline$R \mathrm{rs} \mathrm{cmH}_{2} \mathrm{O} \cdot \mathrm{L}^{-1} \cdot \mathrm{s}$ & $17 \pm 3.9$ & $16.7 \pm 2.7$ & $16.8 \pm 3.0$ & $16.9 \pm 3.6$ \\
\hline$E_{\text {st }, \text { rs }} \mathrm{cmH}_{2} \mathrm{O} \cdot \mathrm{L}^{-1}$ & $12.7 \pm 3.0$ & $12.9 \pm 3.3$ & $12.9 \pm 3.3$ & $15.5 \pm 4.5$ \\
\hline
\end{tabular}

Values are mean \pm SD of 10 patients; PEEPt: total PEEP; PEEPi: intrinsic PEEP; $\triangle F R C$ : difference between end-expiratory lung volume during mechanical ventilation and relaxation volume of the respiratory system; Rint,rs, $\Delta R \mathrm{rs}, R \mathrm{rs}$ : interrupter, additional and total resistance of the respiratory system respectively; Est,rs: static elastance of the respiratory system. ${ }^{*}: \mathrm{p}<0.05$; **: $\mathrm{p}<0.01$ versus PEEP 0 .

(range 2-16 $\mathrm{cmH}_{2} \mathrm{O}$ ). In fact, with $5 \mathrm{cmH}_{2} \mathrm{O}$ PEEP, PEEPt was not significantly increased, reflecting the fact that in most of the patients, the applied PEEP had merely replaced PEEPi, and consequently there was little increase in FRC [10, 15].

\section{Interrupter resistance of the respiratory system}

At all PEEP levels, the values of Rint,rs at baseline $V^{\prime}$ and $\Delta V$ (table 1) were not significantly different among the iso- $V^{\prime}$ and iso- $\Delta V$ experiments and, hence, were averaged (table 2). While Rint,rs did not change significantly with PEEP (table 2), it decreased significantly with increasing $\triangle \mathrm{FRC}$ (fig. 2a). This indicates that PEEP can affect Rint,rs only through its effect on $\Delta F R C$. At constant $\Delta V, R$ int,rs increased linearly with $V^{\prime}$ at all levels of PEEP, according to the following function $[1,3]$ :

$$
R_{\text {int,rs }}=\mathrm{K}_{1}\left(\mathrm{~K}_{2} \times V^{\prime}\right)
$$

Where $\mathrm{K}_{1}$ and $\mathrm{K}_{2}$ are Rohrer's constants [16]. While $\mathrm{K}_{1}$ was independent of $\triangle \mathrm{FRC}$ (fig. $3 \mathrm{a}$ ), $\mathrm{K}_{2}$ decreased significantly with $\triangle \mathrm{FRC}$ (fig $3 \mathrm{~b}$ ).

\section{Additional tissue resistance}

The baseline values of $\Delta R \operatorname{rs}$ during the iso- $V^{\prime}$ and iso- $\Delta V$ experiments were similar and, hence, were averaged. As shown in table 2 , the mean values of $\Delta R$ rs did not change significantly with PEEP. There was also no significant correlation between $\Delta R$ rs and $\triangle$ FRC (fig. 2b).

At each level of PEEP, the data of $\Delta R$ rs obtained in the iso- $V^{\prime}$ and iso- $\Delta V$ experiments could be fitted, in all patients, to a single function of $t$ I (equation 1), as shown in figure 4 for a representative subject. The values of $R_{2}, \tau_{2}$ and $\mathrm{E}_{2}\left(=\mathrm{R}_{2} / \tau_{2}\right)$ thus derived, did not vary significantly with either PEEP or $\triangle \mathrm{FRC}$ (fig. 5).

\section{Respiratory system resistance}

As shown in figure $2 c, R$ rs did not change significantly with $\triangle \mathrm{FRC}$, reflecting the concomitant decrease in Rint,rs (fig. 2a) and increase in $\Delta R \mathrm{rs}$ (fig. 2b). Similarly, Rrs did not change with PEEP (table 2).
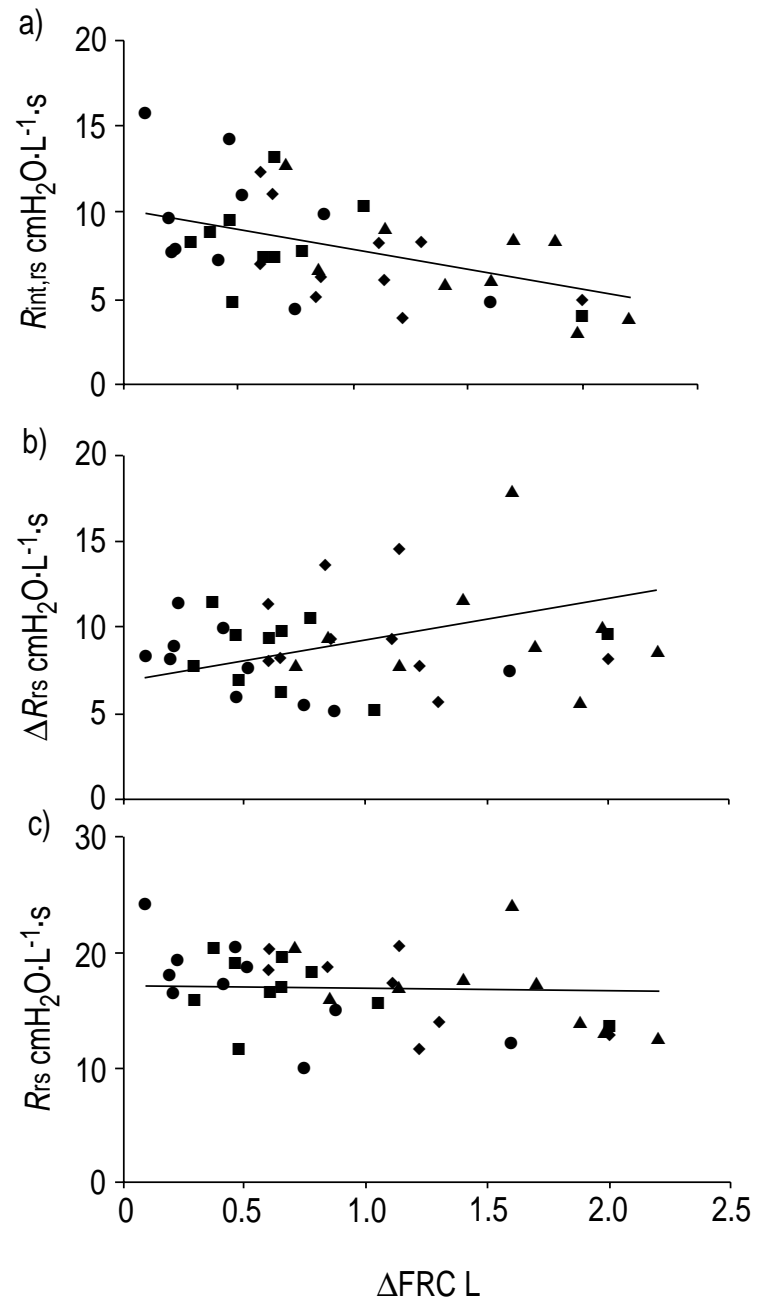

Fig. 2.-Individual relationships of a) interrupter resistance (Rint,rs), b) additional tissue resistance $(\Delta R \mathrm{rs})$ and c) total resistance $(R \mathrm{rs})$ of the respiratory system to the relaxation volume of the respiratory system $(\triangle \mathrm{FRC})$ at $0(\boldsymbol{O}), 5(\boldsymbol{\square}), 10(\diamond)$ and 15 $(\boldsymbol{\Delta}) \mathrm{cmH}_{2} \mathrm{O}$ positive end-expiratory pressure (PEEP) of 10 chronic obstructive pulmonary disease patients. Regression lines over all the experimental points are shown: a) $\mathrm{y}=10.1-2.3 \mathrm{x}, \mathrm{r}=-0.42$, $\mathrm{p}=0.003$; b) $\mathrm{y}=6.8+2.4 \mathrm{x}, \mathrm{r}=0.31$. $\mathrm{p}=\mathrm{NS}$; c) $\mathrm{y}=17.0-0.2 \mathrm{x}, \mathrm{r}=0.03$, $\mathrm{p}=\mathrm{NS}$. 

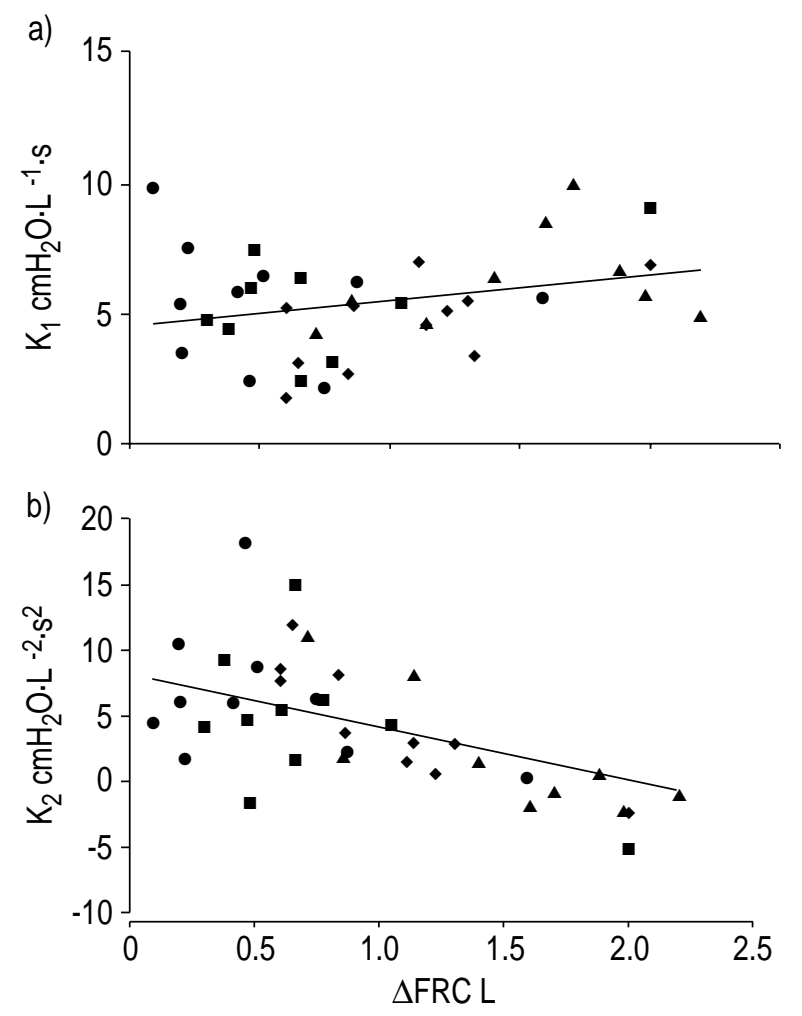

Fig. 3.-Individual relationships of the constants a) $\mathrm{K}_{1}$ and b) $\mathrm{K}_{2}$ (equation 3 ) to the relaxation volume of the respiratory system $(\triangle \mathrm{FRC})$ at $0(\boldsymbol{\bullet}), 5(\boldsymbol{\Delta}), 10(\diamond)$ and $15(\boldsymbol{\Delta}) \mathrm{cmH}_{2} \mathrm{O}$ positive end-expiratory pressure (PEEP) of 10 chronic obstructive pulmonary disease patients. Regression lines over all the experimental points are shown: a) $\mathrm{y}=4.52+0.96 \mathrm{x}, \mathrm{r}=0.16, \mathrm{p}=\mathrm{NS}$; b) $\mathrm{y}=8.21-4.09 \mathrm{x}$, $\mathrm{r}=-0.49, \mathrm{p}<0.001$.

\section{Static elastance of the respiratory system}

The baseline values of $E_{\text {st,rs }}$ were not different between the two sets of experiments and did not change with either PEEP (table 2) or $\triangle \mathrm{FRC}$ (fig. 6).

\section{Discussion}

The main new finding of the present study was that, in COPD patients mechanically ventilated for ARF, the "viscoelastic" behaviour of the respiratory system as reflected by $\Delta R \mathrm{rs}$, does not change with increased lung volume while $R$ int,rs decreases.

\section{Interrupter resistance of the respiratory system}

In normal, anaesthetized paralysed humans, Rint,rs has been found to decrease with PEEP [4, 17], probably reflecting the increased size of the airways as a result of the concomitant increase in lung volume [18]. In the present study, Rint,rs was presented both in relation to PEEP, as is commonly done, and $\triangle F R C$, which is the important parameter. Because the effect of PEEP on $\triangle \mathrm{FRC}$ depends on PEEPi, it is obvious that the results obtained with PEEP in different subjects or studies are not comparable. In fact, the absence of a significant decrease in Rint,rs with PEEP in the patients of the present study (table 2) stems from the complex interplay between PEEPi, dynamic hyperinflation and applied PEEP. Indeed, in COPD patients with tidal expiratory flow limitation, PEEP increases the lung volume only when it approaches or exceeds the PEEPi on ZEEP [10, 14]. Since the present study applied fixed incremental levels of PEEP to all patients, rather than levels tailored to the individual values of PEEPi on ZEEP, which varied markedly among patients (range 2-16 $\mathrm{cmH}_{2} \mathrm{O}$ ), the effect of any given PEEP on FRC varied markedly among patients (fig. 7). In contrast, when Rint,rs was referred to $\triangle \mathrm{FRC}$, a significant negative correlation was found (fig. 2a).

As previously found in COPD patients with $\triangle \mathrm{RF}$ in iso-V experiments on ZEEP [3], Rint,rs decreased linearly with inflation volume (equation 4), the correlation being significant in seven patients. With increasing PEEP, the changes become smaller and patients exhibited a significant correlation. This could reflect progressive longitudinal stretching and narrowing of the airways at high lung volume, as previously described in $\triangle \mathrm{RDS}$ patients [5]. An increase in the interrupter resistance of the chest wall (Rint,w) could also explain the rise in Rint,rs at high lung volume. However, in a previous study on COPD patients on ZEEP, which included measurement of oesophageal pressure, no appreciable $R$ int,w was found [3].

On ZEEP, the values of $\mathrm{K}_{1}$ and $\mathrm{K}_{2}$ were significantly greater in the COPD patients than in normal subjects (table 3 ), as previously described [3]. While in normal subjects $\mathrm{K}_{1}$, but not $\mathrm{K}_{2}$, decreased significantly with increasing lung volume [4], the opposite was found in the COPD patients (fig. 3). The reason for this discrepancy is not clear. It should be noted, however, that $\mathrm{K}_{2}$ is thought to be generated mainly by turbulent flow in the central airways [15]. Using another method, TANTUCCI et al. [19] also found that in COPD patients on ZEEP, $\mathrm{K}_{2}$ decreased with increasing lung volume. The $\mathrm{K}_{2}$ values of the COPD patients were higher than those obtained in previous studies [3, 19]. This may be due, at least in part, to the fact that the present COPD patients were investigated at an earlier stage of ARF than in the previous studies. High values of $\mathrm{K}_{2}$ have also been reported in stable COPD patients [20].

\section{Additional tissue resistance}

The experimental relationships of $\Delta R \mathrm{rs}$ to $t \mathrm{I}$ closely fitted equations 1 and 2 in both iso- $V^{\prime}$ and iso- $\Delta V$ experiments at all four levels of PEEP (fig. 4), as previously found on ZEEP in COPD patients [3] and in normal subjects both on ZEEP and PEEP [4, 21]. These results suggest that, in both COPD patients and normal subjects, the "viscoelastic" behaviour of the respiratory system is independent of lung volume, at least over the volume range used during the iso- $V^{\prime}$ and iso- $\Delta V$ experiments $(\Delta V$ up to $1 \mathrm{~L})$. 

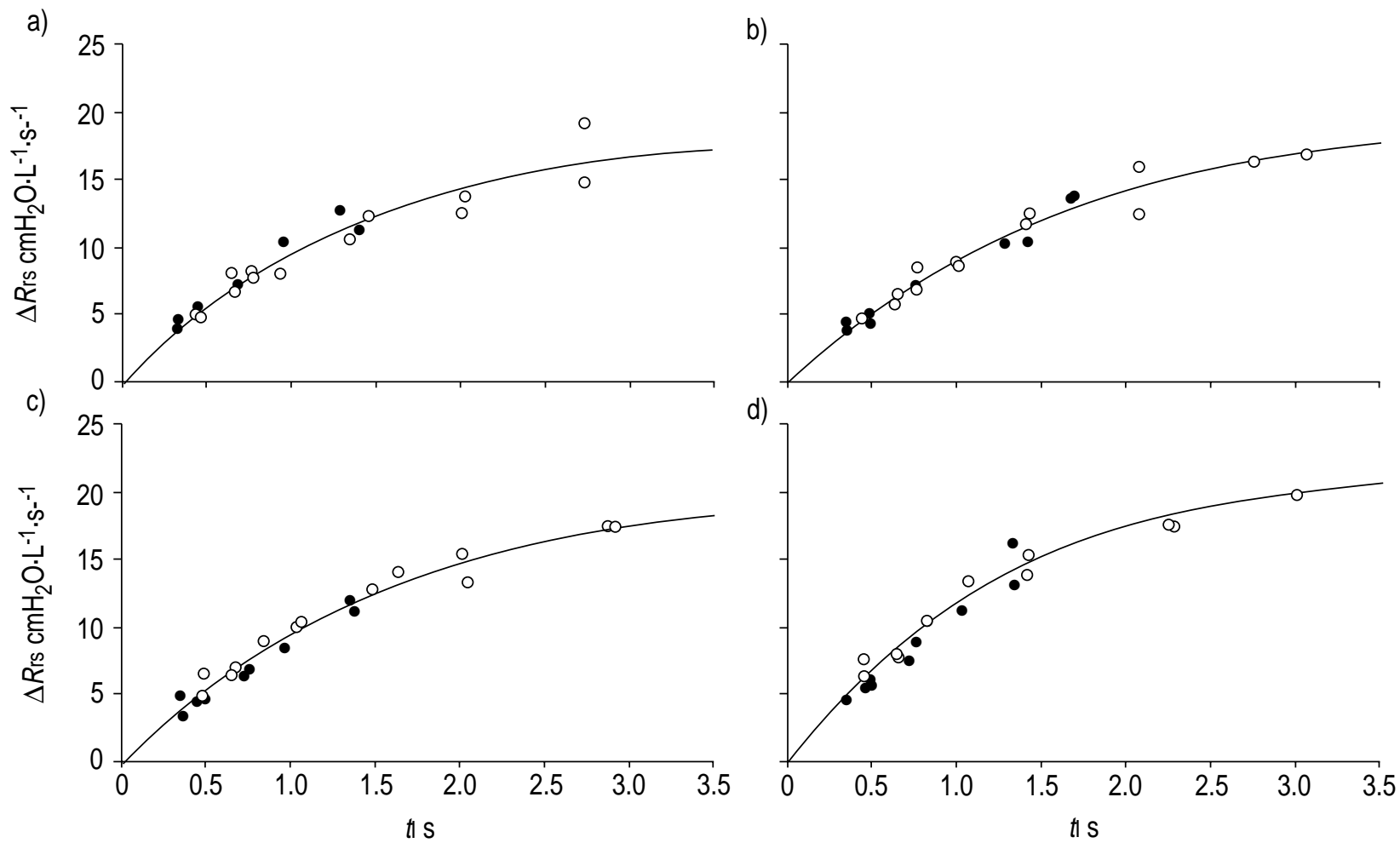

Fig. 4. - Relationships of the additional tissue resistance ( $\Delta R \mathrm{rs})$ to inspiratory time $(t \mathrm{I})$ at a) 0, b) 5 , c) 10 and d) $15 \mathrm{cmH}_{2} \mathrm{O}$ positive endexpiratory pressure (PEEP) obtained in a representative patient during both iso-flow $(\bullet)$ and iso-volume $(O)$ experiments. Solid lines are the regression lines of the fitting of the experimental points to equation $1: \mathrm{a}) \mathrm{r}=0.96, \mathrm{p}<0.001$; $\mathrm{b}$ ) $\mathrm{r}=0.98, \mathrm{p}<0.001$; $) \mathrm{r}=0.98, \mathrm{p}<0.001$; d) $\mathrm{r}=0.98, \mathrm{p}<0.001$.

BEYDON et al. [22], however, studied two COPD patients with ARF, both on ZEEP and PEEP, and found that the results could be adequately fitted to equation 1 in only one patient on ZEEP. In the other instances, the "viscoelastic" behaviour during constant-flow inflation did not accord with the linear viscoelastic model (constant $R_{2}$ and $E_{2}$ ) but implied a markedly volume-dependent elastic element. This discrepancy with the present and previous results [3] may be due to different methodology or patient population. BEYDON et al. [22] occluded the airway at different $\Delta V^{\prime}$ for only $2 \mathrm{~s}$, as compared to $5 \mathrm{~s}$ in the present and previous studies $[3,4,21]$. This short pause is not long enough to allow the viscoelastic pressure to decay to insignificant values according to the values of $\tau_{2}$ in figure $5 \mathrm{~b}$. In view of the complexity and diversity of the pathological changes in the lung of COPD patients, it cannot be excluded that in some instances, the linear viscoelastic model (equation 1) may not be adequate to explain the non-Newtonian behaviour of the respiratory system during constantflow inflation. In the present patients, however, this is not the case. Furthermore, in the present patients, the values of the viscoelastic constants (fig. 5) and $\Delta R \mathrm{rs}$ (fig. 2b) did not change significantly with the PEEPinduced changes in $\triangle \mathrm{FRC}$.

The values of the viscoelastic constants of the present study, both on ZEEP and PEEP, are significantly higher than those found previously in 16 normal subjects on ZEEP [1], in whom $R_{2}, \tau_{2}$ and $E_{2}$ averaged $4.2 \pm 0.6 \mathrm{cmH}_{2} \mathrm{O} \cdot \mathrm{L}^{-1} \cdot \mathrm{s}, 0.9 \pm 0.3 \mathrm{~s}$ and $5.1 \pm 1.2 \mathrm{cmH}_{2} \mathrm{O} \cdot \mathrm{L}^{-1}$, respectively. This could reflect a loss of pulmonary tissue, either anatomical (emphysema) or functional (airway closure) and, in the absence of rheological changes of the remaining tissue, should result in a proportional increase of $R_{2}$ and $E_{2}$ without a change in $\tau_{2}$ [3]. The latter, however, was significantly higher $(\mathrm{p}<0.01)$ in the COPD patients than in normal subjects, probably effecting the complex structural changes and increased time constant inequality within the lungs in COPD patients. However, based on the present results and those of D'ANGELO et al. [21] on normal subjects it can be concluded that these differences were not due to the characteristic pulmonary hyperinflation of COPD. In fact, in both COPD and normal subjects, the simple linear viscoelastic model in figure 1 fits the experimental results at all lung volumes studied. This, however, is not the case in ARDS patients in whom, even on ZEEP, the model in figure 1 failed to fully describe the experimental relationships of $\Delta R$ rs to $t \mathrm{I}$ when inflation volume exceeded 0.71 [5].

Since, in the present COPD patients, the viscoelastic behaviour was independent of $\triangle \mathrm{FRC}$, it is not surprising that in COPD the viscoelastic work per breath does not change with PEEP-induced changes in lung volume [23]. 

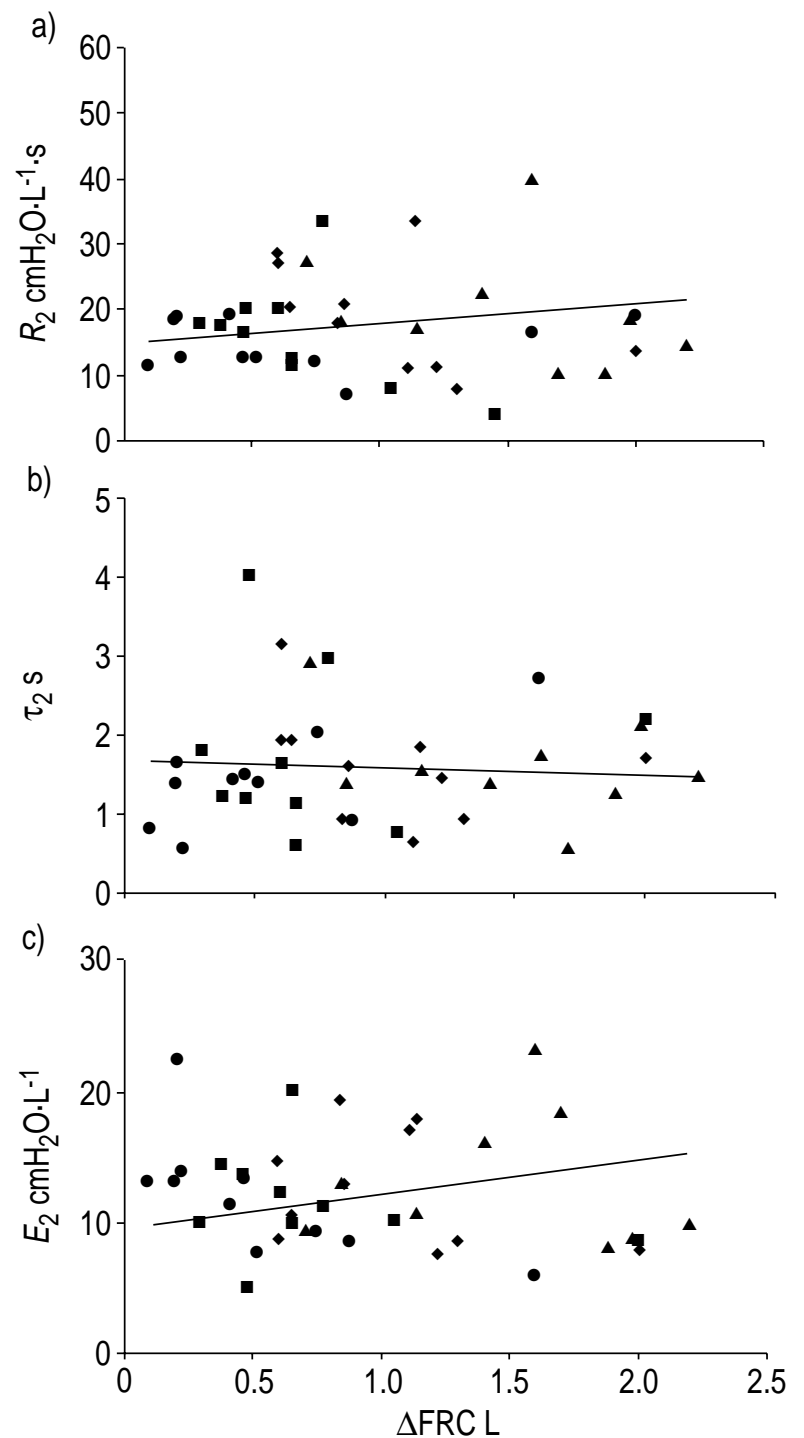

Fig. 5. - Individual relationships of the viscoelastic constants a) $R_{2}$, b) $\tau_{2}$ and c) $E_{2}$ (equations 1 and 2) to the relaxation volume of the respiratory system $(\triangle \mathrm{FRC})$ at $0(\bullet), 5(\boldsymbol{\square}), 10(\bullet)$ and $15(\boldsymbol{\Delta})$ $\mathrm{cmH}_{2} \mathrm{O}$ positive end-expiratory pressure (PEEP) of 10 chronic obstructive pulmonary disease patients. Regression lines over all the experimental points are shown: a) $\mathrm{y}=14.7+3.0 \mathrm{x}, \mathrm{r}=0.36, \mathrm{p}=\mathrm{NS}$; b) $\mathrm{y}=$ $1.7-0.1 \mathrm{x}, \mathrm{r}=-0.13, \mathrm{p}=\mathrm{NS} ; \mathrm{c}) \mathrm{y}=9.6+2.6 \mathrm{x}, \mathrm{r}=0.23$, $\mathrm{p}=\mathrm{NS} . \quad\left(E_{2}=R_{2} / \tau_{2}\right)$.

In conclusion, this is the first systematic study on the effects of high positive end-expiratory pressure on respiratory mechanics in chronic obstructive pulmonary disease patients with acute respiratory failure. The results indicate that respiratory system

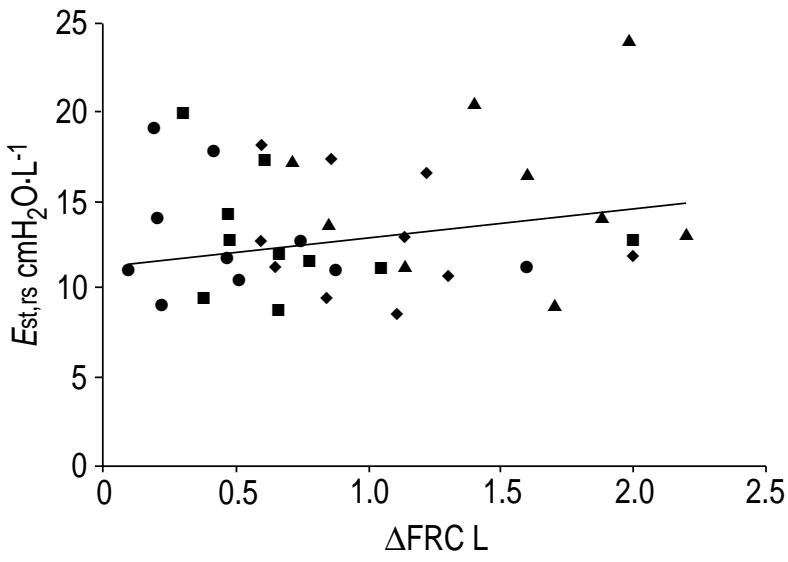

Fig. 6.-Individual relationships of the static elastance of the respiratory system (Est,rs) to the relaxation volume of the respiratory system $(\triangle \mathrm{FRC})$ at $0(\bullet), 5(\mathbf{\square}), 10(\bullet)$ and $15(\mathbf{\Delta})$ $\mathrm{cmH}_{2} \mathrm{O}$ positive end-expiratory pressure (PEEP) of 10 chronic obstructive pulmonary disease patients. Regression line over all the experimental points is shown: $\mathrm{y}=11.1+1.6 \mathrm{x}, \mathrm{r}=0.24$, $\mathrm{p}=\mathrm{NS}$.

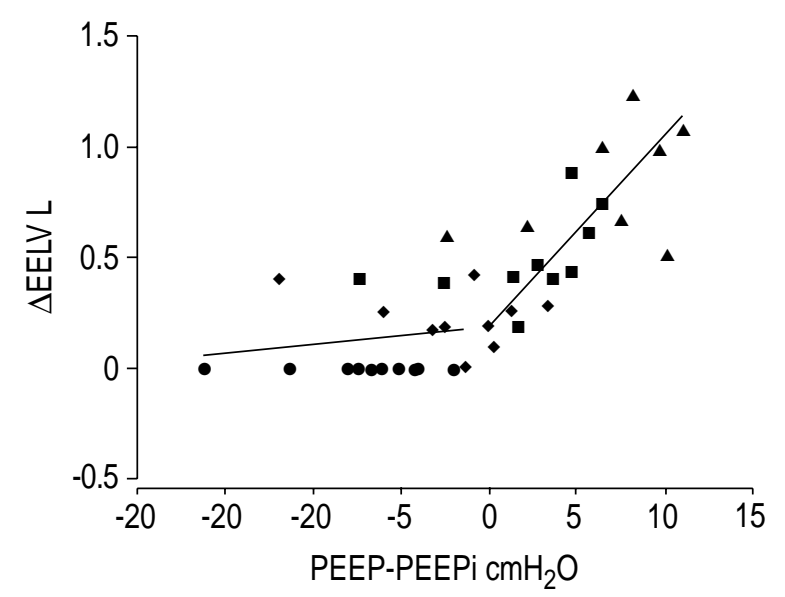

Fig. 7. - Individual relationships of changes in end-expiratory lung volume relative to zero end-expiratory pressure $(\triangle E E L V)$ to positive end-expiratory pressure minus intrinsic positive endexpiratory pressure (PEEP-PEEPi) of 10 chronic obstructive pulmonary disease patients at $0(\bullet), 5(\boldsymbol{\square}), 10(\bullet)$ and $15(\mathbf{\Delta})$ $\mathrm{cmH}_{2} \mathrm{O}$ PEEP. Solid lines are regression lines computed above $(\mathrm{y}=0.2+0.1 \mathrm{x}, \mathrm{r}=0.8, \quad \mathrm{p}<0.001)$ and below $(\mathrm{y}=0.2+0.01 \mathrm{x}, \mathrm{r}=0.14$, $\mathrm{p}=\mathrm{NS})$ PEEP-PEEP $\mathrm{i}=\mathrm{O}$.

interrupter resistance decreases with increasing lung volume due to positive end-expiratory pressure, while the viscoelastic behaviour of the respiratory system, as reflected by the additional tissue resistance, is not altered.

Table 3.-Values of $K_{1}$ and $K_{2}$ of respiratory system in normal subjects and chronic obstructive pulmonary disease (COPD) patients on zero end-expiratory pressure

\begin{tabular}{lccc}
\hline & Patients n & $\mathrm{K}_{1} \mathrm{cmH}_{2} \mathrm{O} \cdot \mathrm{L}^{-1} \cdot \mathrm{s}$ & $\mathrm{K}_{2} \mathrm{cmH}_{2} \mathrm{O} \cdot \mathrm{L}^{-2} \cdot \mathrm{s}^{2}$ \\
\hline Normal subjects [1] & 16 & $1.94 \pm 2.04^{* * *}$ & $0.52 \pm 0.32^{* * *}$ \\
Previous COPD patients [3] & 10 & $5.03 \pm 1.35$ & $2.69 \pm 1.89 *$ \\
Present COPD patients & 10 & $5.39 \pm 2.19$ & $6.34 \pm 4.95$ \\
\hline
\end{tabular}

Values are presented as mean $\pm \mathrm{SD} ; \mathrm{K}_{1}$ and $\mathrm{K}_{2}$ : constants of equation 3 ; ***: $\mathrm{p}<0.001$ between normals and both groups of COPD patients; *: $\mathrm{p}<0.05$ between previous and present COPD patients. 


\begin{abstract}
Acknowledgements. The authors thank the physicians and nursing staff of the Medical Intensive Care Unit of the Centre Hospitalier Lyon-Sud for their valuable cooperation and M. Rabilloud for her help with statistical analysis.
\end{abstract}

\section{References}

1. D'Angelo E, Calderini E, Torri G, Robatto FM, Bono D, Milic-Emili J. Respiratory mechanics in anesthetized paralyzed humans: effects of flow, volume and time. J Appl Physiol 1989; 67: 2556-2564.

2. D'Angelo E, Robatto FM, Calderini E, et al. Pulmonary and chest wall mechanics in anesthetized paralyzed humans. J Appl Physiol 1991; 70: 2602-2610.

3. Guerin C, Coussa ML, Eissa NT, et al. Lung and chest wall mechanics in COPD patients. $J$ Appl Physiol 1993; 74: 1570-1580.

4. D'Angelo E, Calderini E, Tavola M, Bono D, MilicEmili J. Effect of PEEP on respiratory mechanics in anesthetized paralyzed humans. J Appl Physiol 1992; 73: $1736-1742$.

5. Eissa NT, Ranieri MV, Corbeil C, et al. Analysis of behavior of the respiratory system in ARDS patients: effects of flow, volume and time. J Appl Physiol 1989; 70: 7219-7229.

6. Georgopoulos D, Giannouli E, Patakas D. Effects of extrinsic positive end-expiratory pressure on mechanically ventilated patients with chronic obstructive pulmonary disease and dynamic hyperinflation. Intensive Care Med 1993; 19: 197-203.

7. Musch G, Foti G, Cereda M, Pelosi P, Poppi D, Pesenti A. Lung and chest wall mechanics in normal anaesthetised subjects and in patients with COPD at different PEEP levels. Eur Respir J 1997; 10: 2545 2552.

8. Bates JHT, Ludwig MS, Sly PD, Brown K, Martin JG, Fredberg JJ. Interrupter resistance elucidated by alveolar pressure measurement in open-chest normal dogs. J Appl Physiol 1988; 65: 408-414.

9. Morris JF, Koski A, Johnson LC. Spirometric standards for healthy nonsmoking adults. Am Rev Respir Dis 1971; 103: 57-67.

10. Guerin C, Lemasson S, DeVarax R, Milic-Emili J, Fournier G. Small airway closure and positive end-expiratory pressure in mechanically ventilated patients with chronic obstructive pulmonary disease. Am J Respir Crit Care Med 1997; 155: 1949-1956.

11. Bates JHT, Sly PD, Okubo S. General method for describing and extrapolating monotonic transients and its application to respiratory mechanics. Med Biol Eng Comput 1987; 25: 131-135.

12. Kochi TS, Okubo S, Zin WA, Milic-Emili J. Chest wall and respiratory system mechanics in cats: effects of flow and volume. J Appl Physiol 1988; 64: 26362646.

13. Similovski T, Levy P, Corbeil C, et al. Viscoelastic behaviour of lung and chest wall in dogs determined by flow interruption. J Appl Physiol 1989; 67: 22192229.

14. Dunnett CW. A multiple comparison procedure for comparing several treatments with a control. Am Stat Ass J 1955; 50: 1096-1121.

15. Ranieri VM, Giuliani R, Cinnella G, et al. Physiologic effects of positive end expiratory pressure in patients with chronic obstructive pulmonary disease during acute ventilatory failure and controlled mechanical ventilation. Am Rev Respir Dis 1993; 147: 5-13.

16. Rohrer F. Der stromungswiderstand in den menschlichen Atemwegen und der Einfluss der unregelmassigen Verzweigung des Bronchialsystems auf den Atmungsverlauf in verschiedenen Lungenbezirken. Pfluegers Arch Gesamte Physiol Menschen Tiere 1915; 162: 225-299.

17. Cohendy R, Ripart J, Eledjam JJ. The effect of positive end-expiratory pressure on respiratory resistive properties in anaesthetized paralysed humans. Eur Respir J 1994; 7: 286-291.

18. Briscoe WA, Dubois AB. The relationship between airway resistance, airway conductance and lung volume in subjects of different age and body size. $J$ Clin Invest 1958; 37: 1279-1285.

19. Tantucci C, Corbeil C, Chasse M, Braidy J, Matar N, Milic-Emili J. Flow resistance in patients with chronic obstructive pulmonary disease in acute respiratory failure. Am Rev Respir Dis 1991; 144: 384-389.

20. Grimby G, Takishima T, Graham W, Macklem PT, Mead J. Frequency dependence of flow resistance in patients with obstructive lung disease. J Clin Invest 1968; 47: 1455-1465.

21. D'Angelo E, Tavola M, Milic-Emili J. Volume and time dependence of respiratory system mechanics in normal anaesthetized paralysed humans. Eur Respir $J$ 2000; 16: 665-672.

22. Beydon L, Svantesson C, Brauer K, Lemaire F, Jonson B. Respiratroy mechanics in patients ventilated for critical lung disease. Eur Respir J 1996; 9: 262-273.

23. Guerin C, Milic-Emili J, Fournier G. Effect of PEEP on work of breathing in mechanically ventilated COPD patients. Intensive Care Med 2000; 26: 12071214. 